\title{
Prevalence: Knowledge, Attitude and Management Practices of Diabetes Mellitus and Hypertension in Amaoba Ikwuano Abia State Nigeria
}

\author{
*AMADI, ANC; AMOKE, OC; AGBAI, PO \\ College of Natural Sciences, Department of Zoology and Environmental Biology, Michael Okpara University of Agriculture Umudike, \\ Umuahia, Nigeria \\ *Corresponding Author Email: amadi.anthonia@mouau.edu.ng
}

\begin{abstract}
Screening study of diabetes mellitus and hypertension was carried out in Amaoba Ikwuano, Abia State, Nigeria to determine the prevalence of diabetes mellitus and hypertension and to access management practices of the diseases among the subject. Accu-check glucometer strip, blood pressure monitor, weighing balance, height metre were used for the study. Out of 260 subjects. 136(52.30\%) were males and 124(47.70\%) were female. The overall prevalence of diabetes mellitus and hypertension in the study area was $35.38 \%$ and $32.31 \%$ respectively. The prevalence of diabetes mellitus in the study area indicated that males $(41.3 \%)$ were more affected than females $(29.03 \%)$. Also male subjects are more hypertensive $(38.25 \%)$ than females $(28.81 \%)$. There is no significant difference with respect to sex $(\mathrm{p}<0.05)$. Incidence of diabetes mellitus and hypertension showed that males within the age group of 61-70 years have the highest $(38.89 \%)$ followed by females in the same age group $(26.78 \%)$ and the least $(2.94 \%)$ was among age group $20-30$ years in the study area. There was a significant difference between age and sex $(\mathrm{p}<0.05)$. Body Mass Index (BMI) according to sex in relation to diabetes mellitus and hypertension showed that majority of overweight males $(67.85 \%)$ and females $(65.38 \%)$ are diabetic. Questionnaire analysis showed that majority of respondents were aware of diabetes mellitus. Most subjects $(64.62 \%)$ have not been previously diagnose of diabetes mellitus. Knowledge on hypertension showed that most $(96.15 \%)$ are aware of the disease and majority $(67.69 \%)$ have not been previously diagnosed of the disease. Some respondent believed that diabetes is mainly caused by consumption of starchy food $(31.62 \%)$, others identified the cause of hypertension to be obesity (39.26\%). Management of diabetes mellitus were identified to be adhering to diet (29.31\%). Whereas the management of hypertension were identified to be maintaining normal weight (33.57\%). High blood pressure, diabetes mellitus and overweight are prevalent in the study area. There is need for proper health education in the communities for regular screening test and management practices to minimize or avert the risk of complications of late diagnosis.
\end{abstract}

\section{DOI: https://dx.doi.org/10.4314/jasem.v22i12.17}

Copyright: Copyright $\odot 2018$ Amadi et al. This is an open access article distributed under the Creative Commons Attribution License (CCL), which permits unrestricted use, distribution, and reproduction in any medium, provided the original work is properly cited.

Dates: Received: 04 November 2018; Revised: 16 December 2018; Accepted 24 December 2018

Keywords: Prevalence, Diabetes Mellitus, Hypertension, Management Practices

Diabetes mellitus (DM) and hypertension are global health disorders afflicting millions of people worldwide with an ever increasing incidence and prevalence (Wokoma, 2012). Diabetes Mellitus occurs as a result of insufficient insulin production or because of the presence of factors that oppose the production of insulin (Kazeem, 2005). It is a condition in which the patient blood sugar level is high either because insulin production is inadequate or the body cells do not respond properly to insulin or both. Insulin is a hormone that is needed in the body to control the rate at which sugar, starch and other food are converted into glucose required as energy for daily life. The hormone is produced and released into the blood by an organ called "pancreas". This insulin helps to maintain the blood glucose level within a normal range. WHO (1999) puts the normal range between $60-100 \mathrm{mg} / \mathrm{dl}$ (before taking any food for the day, hence this value is called fasting blood glucose. Diabetes mellitus is the fastest growing, long term diseases in terms of number that affects millions of people worldwide with many sufferers unaware they even have the disease. In Nigeria, an estimated number of over 3 million Nigerians between age 25 and 79 years have diabetes, while 2.5 million Nigerian living with the condition are unaware and undiagnosed according to the World Health Organization standard (Saduwa, et. al 2015). The rate of hypertension in Nigeria has moved from $11-20 \%$ and now increasing to $40 \%$ (Obinna and Odinkemalu, 2015). In Africa, more than 40-50\% of adult in many countries were estimated to be hypertensive (WHO, 2012). This is bad because the condition can damage the heart, or the brain leading to stroke, heart failure, systemic or pulmonary failure due to the presence of combination of some risk factors such as: tobacco use, unhealthy diet and obesity, 
physical in activity and harmful use of alcohol, diabetes mellitus and hypolipidaemia (Obinna and Odinkemalu, 2015). Diabetes mellitus may have various complications among which are diabetic nephropathy that could lead to kidney dysfunction, foot ulcer and diabetic retinopathy that could lead to total blindness if not properly managed (Boussageon et.al, 2011). In male, it may cause erectile dysfunction. It has been discovered that close to $60 \%$ of male with diabetes have erectile dysfunction (Adesina, 2015). Diabetes mellitus leads to a lot of infections as the ability to fight infection is weakened. Many factors may lead to high blood pressure, it may be a primary disease entity (in which case it is referred to as essential hypertension or symptoms of a number of disorders affecting the kidney that is reno-vascular hypertension or it may be due to disorder of the blood vessels or the adrenal glands. Such infections include: typhoid fever, tonsillitis which may lead to hypertension (Oyekole, 2015).The normal average blood pressure in a young adult is $120 / 80$ that is, 120 millimeters for the systolic blood pressure and 80 millimeter for the diastolic blood pressure. Persistent reading above 140 systolic and 90 diastolic blood pressure actually indicate the patient is hypertensive or have a high blood pressure (Oyekole, 2015). This present study sought to determine the prevalence of diabetes mellitus and hypertension among the inhabitants of Amaoba Ikwuano Abia State and knowledge, attitude and management practices of the respondents regarding diabetes mellitus and hypertension.

\section{MATERIALS AND METHOD}

The study was conducted in Amaoba in Ikwuano Local Government Area Umuahia in Abia State. The total population sampled was 260 from Amaoba. The subjects were investigated to evaluate the incidence of diabetes mellitus and hypertension in the study areas and to access their knowledge and management practices of the diseases. The design adopted for this research is epidemiology survey design. It tries to determine the incidence of diabetes mellitus using an accu-chek glucometre and the incidence of hypertension using a blood pressure monitor and their knowledge and management practices using questionnaires. Other instruments used are Hanson bathroom scale weighing balance, height metre, soft clix lancet, cotton wool, methylated spirit.

Blood Glucose Measurement: Blood glucose level was measured using accu-chek glucometer by fasting blood sugar (FBS) method. An accu-chek glucometre with a measuring range $100-600 \mathrm{mg} / \mathrm{dl} \quad(0.6-33.3$ $\mathrm{mmol} / \mathrm{L})$. Accu-chek active test strip was inserted into the glucometer with the appropriate code chip and the glucometer automatically turned on. A cotton wool was used to apply methylated spirit on the individual's fingertip (usually the third finger) to sterilize the area. Soft clix lancing device was prepared for pricking the fingertip and a small drop of blood was applied on the middle of the green colored square on the test strip after a dropping sign was displayed on the glucometer. The glucometer measured and displayed the level of glucose in the individual's blood which was recorded. The values obtained were classified according to WHO standards. A result of $60-100 \mathrm{mg} / \mathrm{dl}$ shows normal sugar level, 100-120 shows pre-diabetes while 120 and above is diabetic according to WHO (2012; 1999).

Blood Pressure Measurement: The air tube of the blood pressure monitor was connected to the central unit with the arm cuff wrapped round the individual's arm. Blood pressure were measured on the left arm and placed horizontally close to the heart with the arm horizontal on a table with the individual in a sitting position after resting for about 5-10 minutes. The central unit was turned on as the arm cuff begins to inflate and after 1-2 minutes, the systolic and diastolic blood pressure automatically display after deflation (Abdullahi etal, 2009).

Weight Measurement: The weight was measured with a weighing balance graduated in kilograms $(\mathrm{kg})$ from $0-120 \mathrm{~kg}$. The individual stand erects on the weighing balance without touching anything. The weight was read and recorded to the nearest $0.1 \mathrm{~kg}$.

Height Measurement: The height of the individual was measured with a height meter. Each individual stands on the platform with feet parallel to each other and with heels, shoulder and back touching the height meter. The head was held comfortably erect and arms hang at their sides in a natural manner. The height was read and recorded to the nearest $0.1 \mathrm{~cm}$. Body Mass Index (BMI) was calculated as an index weight for height $\left(\mathrm{kg} / \mathrm{m}^{2}\right)$ and categorized according to WHO standards.

Ethical Approval: Ethical permission was obtained from the Ethical Committee of the Department of Zoology and Environmental Biology, Michael Okpara University of Agriculture Umudike Abia State Nigeria. Permission was obtained from the village head of Amaoba Ikwuano on the agreement that the subjects' anonymity must be maintained and that findings would be treated with utmost confidentiality. Advocacy call was made to enlighten the people on the importance of the study after which consent of the subjects were sought and received before commencement of the study. 
Statistical Analysis: Data was computed statistically using chi-square and simple percentage, a P-value $<0.05$ was considered statistical significant whereas $\mathrm{P}>0.05$ was considered insignificant.

\section{RESULTS AND DISSCUSION}

The overall prevalence of diabetes mellitus in male was $56(41.30 \%)$, female $36(29.01 \%)$ and hypertension was $52(38.25 \%)$ in males $32(28.81 \%$ ) in females (Table 1). Table 2 represents the incidence of diabetes mellitus and hypertension in relation to age. Most males $(38.89 \%)$ in the study area within the age group of 60 - 70 are affected. Followed by those within the age group of $51-60(29.63 \%)$ while no case was recorded within the age group 20 - 30 in both areas. The occupational status of the respondents shows that in urban area civil servant has the highest number (34.61\%) followed by students $(31.52 \%)$ then traders $(17.39 \%)$, self-employed (14) then least is farmers $(5.43 \%)$ while in the rural areas majority are farmers $(83.15 \%)$ followed by traders $(8.42 \%)$ then least civil servants $(7.59 \%)$ (Table 3 ). The incidence of Body Mass Index (BMI) according to sex in relation to diabetes mellitus and hypertension show that out of 56 males that are diabetic in the study area $8(14.29 \%)$ are obsessed and $38(67.85 \%)$ are overweight. Also out of 52 males that are hypertensive $34(65.38 \%)$ are overweight and 8(15.38\%) are obessed. Among the females, out of 36 that are diabetic, $22(61.11 \%)$ are overweight and $6(16.67 \%)$ are obessed, and also out of 32 that are hypertensive $8(25.00 \%)$ are obsessed (Table 4). Respondents response knowledge about diabetes mellitus and hypertension indicate that majority (92.31\%) of subjects are aware of diabetes mellitus as a disease. Also majority (64.62\%) have not been previously diagnosed of the diseases (Table 5). High consumption of starchy food was indicated to be the main cause of diabetes. Witchcraft was not seen as the cause of diabetes mellitus. On hypertension, respondents claimed that obesity is the main (39.26\%) cause of hypertension, followed by stress $(33.78 \%)$, hereditary $(15.06 \%)$, too much salt intake while the least $(5.02 \%)$ has no idea of the cause of hypertension (Table 6). Frequent urination was observed to be the main symptom of diabetes mellitus (61.53\%). Followed by weakness $(30.76 \%)$. Shortness of breath $(32.03 \%)$ was observed to be the main symptom of hypertension followed by chest pain $(30.68 \%)$ other are blurred vision $(17.46 \%)$ and constant headache (14.81\%) (Table 7). Table 8 indicates that, adhering to diet was observed to be the highest $(29.31 \%)$ perceived management practices, followed by medication $(26.89 \%)$, routine screening $(25.86 \%)$, exercise $(17.93 \%)$ then No idea $(3.44 \%)$ majority $(56.66 \%)$ of them had no idea about the management practices, followed by adhering to diet (20.66\%), routine screening $(13.33 \%)$ proper medication $(6.66 \%)$ then exercise $(2,66 \%)$. Management practices of hypertension among the respondents reveal that majority $(33.57 \%)$ agreed that maintaining normal weight is very important in maintaining normal blood pressure followed by routine check of blood pressure $(26.93 \%)$ then adhering to medication $(18.81 \%)$. The method of treatment of both diseases are observed by majority $(74.62 \%)$ of the respondents and agreed that they are best treated in the hospital, followed by Herbal treatment (19.23\%), chemist $(3.85 \%)$ and self-medication $(2.31 \%)$ (Table 9$)$.

Table 1: Overall prevalence of Diabetes Mellitus and Hypertension

\begin{tabular}{lll}
\multicolumn{3}{c}{ according to sex and location } \\
\hline Sex & $\begin{array}{l}\text { Frequency } \\
(\mathbf{N})\end{array}$ & $\begin{array}{l}\text { Prevalence \& } \\
\text { Percentage }(\%)\end{array}$ \\
\hline $\begin{array}{l}\text { Diabetes Mellitus (Dm) } \\
\text { Male }\end{array}$ & 5 \\
Female & $136(52.30 \%)$ & $6(41.3)$ \\
Total & $124(47.70)$ & $36(29.03)$ \\
Hypertention & $260(100)$ & $92(35.38)$ \\
Male & & \\
Female & $136(52.30)$ & $52(38.25)$ \\
Total & $124(47.70)$ & $32(28.81)$ \\
\hline
\end{tabular}

Table 2: Distribution of the incidence of Diabetes Mellitus and Hypertension in relation to age group and sex

\begin{tabular}{lllll}
\hline Age Group & Male Freq & Percent & Female Freq & Percent \\
\hline $20-30$ & 0 & 0.00 & 2 & 2.94 \\
$31-40$ & 10 & 9.26 & 18 & 26.47 \\
$41-50$ & 18 & 16.67 & 10 & 14.71 \\
$51-60$ & 32 & 29.63 & 18 & 26.70 \\
$61-70$ & 42 & 38.89 & 18 & 26.70 \\
$70+$ & 6 & 5.56 & 2 & 2.94 \\
TOTAL & $\mathbf{1 0 8}$ & $\mathbf{1 0 0}$ & $\mathbf{6 8}$ & $\mathbf{1 0 0}$ \\
\hline
\end{tabular}

Table 3: Distribution of respondents based on occupational status OCCUPATIONAL FREQUENCY PERCENT

\begin{tabular}{lll} 
STATUS & $(\mathrm{N})$ & $(\%)$ \\
\hline Civil servant & 90 & 34.61 \\
Students & 84 & 31.52 \\
Farmers & 14 & 5.43 \\
Self-employed & 28 & 10.86 \\
Trader & 46 & 17.39 \\
TOTAL & $\mathbf{2 6 0}$ & $\mathbf{1 0 0}$ \\
\hline
\end{tabular}

Table 4: Incidence of body Mass Index (BMI) in male and female with Diabetes Mellitus (DM) and Hypertension (HBP)

\begin{tabular}{lllll}
\multicolumn{4}{c}{ Table 4: Incidence of body Mass Index (BMI) in male and female with Diabetes Mellitus (DM) and Hypertension (HBP) } \\
\hline & Male & \multicolumn{3}{c}{ Female } \\
\hline BMI INTERNAL & NO. OF DM (\%) & NO. OF HBP (\%) & NO. OF DM (\%) & NO. OF HBP (\%) \\
$18.5-25.0 \mathrm{~kg} / \mathrm{m}^{2}$ & $10(17.86)$ & $10(19.23)$ & $8(22.22)$ & $8(25.00)$ \\
Normal & & & & \\
$25.0-29.0 \mathrm{~kg} / \mathrm{m}^{2}$ & $38(67.86)$ & $34(65.38)$ & $22(61.11)$ & $16(50.00)$ \\
$\begin{array}{l}\text { Overweight Above } 30 \mathrm{~kg} / \mathrm{m}^{2} \\
\text { Obsess }\end{array}$ & $8(14.29)$ & $8(15.39)$ & $6(16.67)$ & $8(25.00)$ \\
Total & $\mathbf{5 6 ( 1 0 0 )}$ & $\mathbf{3 2}(\mathbf{1 0 0})$ & $\mathbf{3 6}(\mathbf{1 0 0})$ & $\mathbf{3 2}(\mathbf{1 0})$ \\
\hline
\end{tabular}


This study showed that males, were more diabetic than females. This disagrees with the study of Ngwu and Nwabueze (2008) who observe that females are more affected. The observation from this study could be attributed to the fact that men tend to distribute fat more readily around the liver or other body organs unlike the women who deposit fat under the skin and the hip. Also alcohol intake and dietary habit can influence the way the gain weight and can equally make then insensitive to insulin (Longue, et.al, 2011). It was also observed that males, were more hypertensive than the females.

Table 5: Distribution of Respondents On The Knowledge Of Diabetes Mellitus and Hypertension

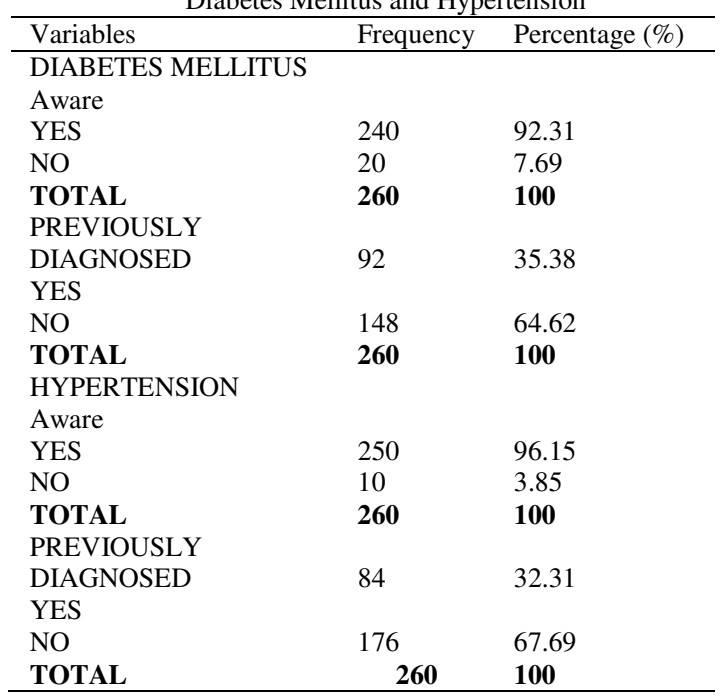

Table 6: Distribution of respondents based on the causes of Diabetes Mellitus and Hypertension

\begin{tabular}{lll}
\hline CAUSES & $\begin{array}{l}\text { FREQUENCY } \\
(\mathbf{N})\end{array}$ & $\begin{array}{l}\text { PERCENT } \\
(\boldsymbol{\%})\end{array}$ \\
\hline DIABETES MELLITUS & & \\
Witchcraft & 0 & 0.00 \\
High consumption of sugar & 72 & 27.90 \\
Consumption of starchy food & 82 & 31.62 \\
Lack of exercise & 22 & 8.37 \\
Hereditary & 36 & 13.95 \\
High alcohol intake & 18 & 6.51 \\
Overweight & 18 & 6.97 \\
No idea & 12 & 4.65 \\
TOTAL & $\mathbf{2 6 0}$ & $\mathbf{1 0 0}$ \\
HYPERTENSION & & \\
Obesity & 102 & 39.26 \\
Stress & 88 & 33.78 \\
Hereditary & 40 & 15.06 \\
Witchcraft & 0 & 0.00 \\
Too much salt intake & 18 & 6.84 \\
No idea & 12 & 5.02 \\
TOTAL & $\mathbf{2 6 0}$ & $\mathbf{1 0 0}$ \\
\hline
\end{tabular}

This could be as a result of too much economic hardship and stress encountered by the males in trying to take case of the family. Subjects having hypertension are likely to have diabetes mellitus from this study, this is in agreement with Bernoho et.al,
(Berraho, et al., 2012) who observed that there is considerable evidence from an increase in prevalence of hypertension in diabetic persons and vice-versa. Incidence of diabetes mellitus and hypertension according to age in the study area showed that males within the age group of $61-70$ years have the highest, followed by female in the same age group. This could be because the disease is a degeneration disease and progresses with age.

Table 7: Distribution of respondents based on the signs and symptom of Diabetes Mellitus and Hypertension

\begin{tabular}{lll}
\hline SIGNS AND SYMPTOMS & $\begin{array}{l}\text { FREQUENCY } \\
(\mathbf{N})\end{array}$ & $\begin{array}{l}\text { PERCENT } \\
(\mathbf{\%})\end{array}$ \\
\hline DIABETES MELLITUS & & \\
Frequent urination & 160 & 61.53 \\
Sugar ant around the urine & 10 & 3.84 \\
Weakness & 80 & 30.76 \\
No idea & 10 & 3.84 \\
TOTAL & $\mathbf{2 6 0}$ & $\mathbf{1 0 0}$ \\
HYPERTENSION & & \\
Chest pain & 80 & 30.68 \\
Constant headache & 38 & 14.81 \\
Shortness of breath & 96 & 37.03 \\
Blurred vision & 46 & 17.46 \\
No idea & 0 & 0.00 \\
TOTAL & $\mathbf{2 6 0}$ & $\mathbf{1 0 0}$
\end{tabular}

Table 8: Distribution of respondents based on the management of Diabetes Mellitus and Hypertension

\begin{tabular}{lll}
\hline Management Practices & $\begin{array}{l}\text { Frequency } \\
(\mathbf{N})\end{array}$ & $\begin{array}{l}\text { Percent } \\
(\boldsymbol{\%})\end{array}$ \\
\hline DIABETES MELLITUS & & \\
Exercise & 44 & 17.93 \\
Medication & 68 & 26.89 \\
Routine screening & 64 & 25.86 \\
Adhering to diet & 76 & 29.31 \\
No idea & 8 & 3.44 \\
TOTAL & $\mathbf{2 6 0}$ & $\mathbf{1 0 0}$ \\
HYPERTENSION & & \\
Controlled salt intake & 42 & 15.86 \\
Maintaining weight at normal & 88 & 33.57 \\
Routine check of blood pressure & 70 & 26.93 \\
Adhering to medication & 48 & 18.81 \\
No idea & 12 & 4.79 \\
TOTAL & $\mathbf{2 6 0}$ & $\mathbf{1 0 0}$ \\
\hline
\end{tabular}

Table 9: Distribution of respondents based on the method of treatment of Diabetes Mellitus and Hypertension

\begin{tabular}{lll}
\hline $\begin{array}{l}\text { METHOD OF } \\
\text { TREATMENT }\end{array}$ & $\begin{array}{l}\text { FREQUENCY } \\
(\mathrm{N})\end{array}$ & $\begin{array}{l}\text { PERCENT } \\
(\%)\end{array}$ \\
\hline Chemist & 10 & 3.85 \\
Hospital & 194 & 74.62 \\
Herbal & 50 & 19.23 \\
Self-medication & 6 & 2.31 \\
No idea & 0 & 0.00 \\
TOTAL & 260 & 100 \\
\hline
\end{tabular}

The least was among age group 20-30 years. Ngwu et. al, (2012) also observed that prevalence of diabetes increasing with age and as people age their relative amount of body fat tends to increase even if their weight stays stable and muscle mass tend to increase (Saduwa, et.al, 2015). This makes the aged more 
predisposed to diabetes mellitus. Akinkugbe (1997) and Henry Unaeze et.al, (2012) noted that the risk of diabetes mellitus increases $3-4$ folds after the age of 44 years in Nigeria. The high prevalence of overweight and obesity are risk factors to diabete among the study population and these could trigger diabetes in future. Since overweight and obesity are risk factors to diabetes and sedentary life style of most adults promotes over weight and obesity these could also trigger hypertension (Henry Unaeze et.al; 2012). Most diabetes and hypertensive patients are unaware of their health status and have not subjected themselves to screening test. This is in agreement with Ugwu et.al, (2012) Amadi and Nwokolo (2014) who observed that most diabetic and hypertensive patients are only aware of their status not until they reach complication stage. Early detection of diabetes may change the course of the disease and early intervention can lead to delay in progression and complication (Whitney and Rolfes; Saduwa, et.al, 2015) Diabetes mellitus and hypertension cause prolong ill-health, impose morbidity and mortality risks, necessitates a change in life style with a meticulous daily routine and long term self-care (Ngwu, et.al, 2012 ). High consumption of starchy food was indicated by subjects to be the main cause of diabetes. Most respondents attributed the causes of diabetes mellitus to be consumption of starchy food. This is in line with observation made by Franz et al., (2010) that inability to adhere to diet and provide balanced diet could lead to diabetes. Although, Kazeem (2005) observed that diabetes has no clear cut causes. Majority of the Respondents believed that obesity is the cause of hypertension this agrees with the signs and symptoms observed by Oyekole (2015) which include; shortness of breath, obesity, constant headache. Most respondents attributed frequent urination as most significant signs and symptoms of diabetes mellitus others include excessive thirst, blurred vision, while the symptoms of hypertension is believed to be shortness of breath, this agrees with Oyekole (2015) who observes that obesity, chest pain shortness of breath are some of the signs of hypertension. A good number of the respondents had good knowledge of Diabetes mellitus but have not subjected themselves to screening or been previously diagnosed of the disease. While some are aware and have been previously diagnosed of the disease. This is in agreement with Anjana et.al (2011) who observed could be a result of access to medical facilities.Most respondents believed that adhering to prescribed diet was the best management procedure for diabetes mellitus. This is in agreement with Kazeem (2005) dietary management of diabetes mellitus. They also believe that maintaining normal weight is the most significant to the management of hypertension. It was observed in the study that diabetes mellitus and hypertension are co-disease that occurs at the same time in most patients. This result is in agreement with Epstain and Sower (1992) who observed that diabetes mellitus and hypertension are common diseases that co-exist at a greater frequency than chance alone would predict. There is a weak positive relationship existing between the number of males and females with diabetes mellitus and hypertension according to age indicating that age is an insignificant contribution to the number of males and females affected with diabetes mellitus and hypertension. Smith (1994) observed that diabetes affects all ages of our population, Saduwa et.al, (2015) have identified juvenile onset (insulin dependent) diabetes as the type that affects the adult onset (Non-insulin dependent) diabetes as the type that affects the elderly. Observations from this study showed that diabetes mellitus and hypertension are coailments that affect both male and female who are equally exposed to the same risk factor though more in males than in females and also increases with age and mostly found more among the elderly, overweight and obese. There is therefore need for intervention of the relevant stakeholders to make legislations that encourage production of fruits and vegetables for the benefit of all. Make screening kits available in all health centres. There should be national campaign on radio and other mass media to educate the populace on regular screening of diabetes mellitus and hypertension for early dictation and proper management.

\section{REFERENCES}

Abdollahi, AA; Qorbani, M; Salehi, A; Mansourian, M (2009). ABO blood groups distribution and cardiovascular major risk factors in healthy population. Iranian Public Health Journal, 38:123-126.

Adesina, O (2015). 2015 World Diabetes Day. Sunday Sun, p. 13. Available at www.sunnewsonline.com. Acessed on 15/11/15.

Akinkugbe, OO (1997). Non-communicable disease in Nigeria. Final report of National Survey. Federal Ministry of Health and Social Servics, Lagos, 64 -90.

Amadi, ANC; Nwokolo, IU (2014). Biological Screening, knowledge and Management of diabetes mellitus in Obohia Ahiazu, Mbaise Imo State, Nigeria; Animal Research Internation vol. 11 (3); 2057 -2062.

Anjana, RM; Ali, MK; Pradeepa, R; Deepa, M; Unnikrishnan, R; Rema, M; Viswanathan, M 
(2011). The need for obtaining accurate nationwide estimates of diabetes mellitus prevalence in India: Rationale National study on diabetes. India Journal Resources, 113:369-380.

Berraho, MEl; Y; Benslimane, K; Rhazi, M (2012). Hypertension and type 2 diabetes: a cross sectional study in Morocco. The Pan African Medical Journal, 11:52.

Boussageon, R; Bejan AT; Saadatian- Elahi, M (2011). Effect of intensive glucose lowering treatment on all causes of mortality, cardiovascular death and microvascular events in type 2 diabetes: meta-analysis of randomized controlled trial. Basic Medical Journal, 34:4169.

Epstein, M; Sower, JR (1992). Diabetes mellitus and hypertension: a co-disease. Amer. Heart Assoc. 19:403-418.

Franz, MJ; Power, MA; Leontos, C; Holzmeister, LA; Kulkarni, K; Monk, A; Weldel, N; Gradwell, E (2010). The evidence of medical nutrition therapy for type 1 and type 2 diabetes melltus for adult. $J$. Amer. Diet Assoc. 110:185-1889.

Henry-Unaeze, HN; Ngwu, EK; Allison, CC (2012). Hospital attendance and Prevalence of diabetes mellitus and hypertension among adult traders in Aba, Abia State. J. Dietitians Assoc. Nig.3:63.

Kazeem, A (2005). What you need to know about diabetes care. Diabetes Care, 2:2-5.

Longue, J; Walker, J; Colhoun, HM (2011). Do men develop type 2 diabetes mellitus at lower body mass indices than women? J. Diabetologia, 321345.

Ngwu, EK; Nwabueze, AM (2008). Prevalence and presentation of diabetes mellitus among patients attending University of Nigeria Nsukka Medical Centre. Nig. J. Nutri. Sci. 29(1):216-231.
Ngwu, EK; Nwabueze, AM; Ubong David (2012) Diabetes screening; A case study of Nsukka urban Enugu State. Journal of Dietician Association of Nigeria Vol. 3, 20112

Obinna, D; Odinkemelu, N (2015). The rate of hypertension in Nigeria, Daily Sun, p22. Available at http://www.sunnewsonline.com. Accessed on $07 / 03 / 15$

Oyekole, D (2015). High blood pressure: Coping with diseases. The Nations, p5.Available at http:// www.thenationsonlinenews.com. Accessed on $07 / 03 / 15$

Saduwa, P;Ukpabio, P; Rukayat, J (2015). How to manage diabetes. The Nations, p.58. Available at http://www.thenationsonlinenewspaper.com. Accessed on 07/03/15.

Smith, IF (1994). Current trends in the management of diabetes. Nig. J. Nutri. Sci. 5(2):76-86.

Whiteney, E; Roltes S R (2008). Hypertension. In understanding Nutrition $11^{\text {th }}$ ed. Thompson Wadsworth, Belmont U.S.A pp 632 -636.

Wokoma, FS (2012). Gestational diabetes mellitus in a Nigeria antenatal population and associated diseases. Tropic. J. Obstetrics Gyne. 18:56-60.

World Health Organization (1999). Development of non-communicable disease: surveillance, definition, diagnosis and classification of diabetes mellitus and its complications. Geneva WHO Report, 342-346.

World Health Organization (2012). New highlight on increase of hypertension, diabetes mellitus. Geneva Health Statistics, 844:24-30. 